\title{
Nuevo enfoque de la educación inclusiva y su articulación con la práctica docente y no docente
}

\author{
New approach to inclusive education and its relationship to teaching practice \\ and non-teaching
}

Patricia Beatriz Toral Ganoza.

Centro Educativo Básica Especial San Antonio.

\section{RESUMEN}

La Educación inclusiva es una necesidad urgente en el sistema educativo peruano. La ley de educación expresa que esta es un derecho para todos sin distinción, sin embargo la educación para niños y niñas con habilidades especiales ha estado encerrada en colegios especiales, limitando a sus participantes a una educación confinada, impidiendo una interacción social con sus coetáneos y su socialización en su medio. La investigación que se presenta aspira a ofrecer un aporte en cuanto a la actualización de los docentes y no docentes que laboran en la educación básica especial y en la educación básica regular, se propone un programa de capacitación en Educación Inclusiva y su nuevo enfoque para contribuir a superar la condición de los niños y niñas con necesidades educativas especiales para una integración social.

Descriptores: Educación inclusiva, programa de capacitación para docentes.

\begin{abstract}
Inclusive education is an urgent need in the Peruvian educational system. The Education Act states that this is a right for all without distinction, however education for children with special abilities have been locked up in special schools, limiting participants to a confined education, avoiding social interaction with peers and socialization in their midst. The research presented aims to provide input regarding the updating of teaching and non-teachers working in special and basic education in regular primary education, it is proposed a training program in Inclusive Education and its new approach to help to overcome the condition of children with special educational needs for social integration.
\end{abstract}

Keywords: Inclusive Education, training program for teachers.

\section{INTRODUCCIÓN}

La Declaración de Salamanca (1994) recomienda que la persona con necesidades educativas especiales deben tener acceso a una institución regular, la cual debe acogerla ubicándola como centro de su quehacer educativo. De este modo, estas escuelas inclusivas constituyen el medio más eficaz para combatir actitudes discriminatorias. En esa misma dirección la Convención sobre los Derechos de las Personas con discapacidad [1] plantea desarrollar la personalidad, talentos y creatividad de las personas con discapacidad para que participen en todos los ámbitos y tareas de una sociedad libre.

En el Perú aproximadamente el $10 \%$ de la población es discapacitada, a los que hay que atender escrupulosamente teniendo en cuenta el derecho que les asiste como cualquier otra persona, para ello, La Ley General de Educación [2] en concordancia con la Ley General de las Personas con Discapacidad aseguran la atención educativa oportuna de tal manera que, puedan integrarse a la educación regular, de acuerdo a las políticas del Estado, que garantizan desarrollar y ejecutar planes pilotos, programas, proyectos y convenios, en lo que se le ha llamado "La Década de la Educación Inclusiva 2003-2012". [3]

El dirigir una institución de educación especial, en un contexto como el peruano que se caracteriza por su diversidad, se convierte en todo un reto que un docente de vocación y comprometido con su sociedad debe asumir con diligencia y serenidad, respaldándose en los aportes científicos de la psicología, pedagogía, sociología y todas las otras disciplinas que han hecho grandes aportes en este campo en estas últimas décadas.

Es importante mencionar a Vigotski como un propulsor de la educación inclusiva ya que 
planteaba... "que la educación de los niños deficientes no se diferencia de la educación de los niños normales, que los primeros pueden asimilar los conocimientos y desarrollar habilidades de manera a la de sus coetáneos. No obstante, es imprescindible investigar y utilizar métodos, procedimientos y técnicas específicas para lograr este desarrollo" [4]. La autora de la tesis concuerda con el autor mencionado y sostiene que los postulados de Vigotski han contribuido decididamente al enfoque de la educación inclusiva.

La investigación que se presenta aspira a ofrecer un aporte en cuanto a la actualización en la educación inclusiva y su nuevo enfoque, con una visión integral y atenta de las potencialidades con que cuenta el personal docente y no docente del Centro Educativo Básica Especial Particular Juan Pablo II. Para lo cual se plantea algunas interrogantes:

¿Qué antecedentes y fundamentos históricos, sociológicos y pedagógicos existen respecto a la capacitación en la educación inclusiva y su nuevo enfoque como parte de la actividad pedagógica profesional de dirección?

¿Cómo se manifiesta la educación inclusiva y su nuevo enfoque en el personal docente y no docente del Centro Educativo Básica Especial Particular Juan Pablo II como parte de la actividad pedagógica profesional de dirección?

¿Qué sustento teórico-metodológico servirá de exigencias para diseñar un programa de capacitación en la educación inclusiva y su nuevo enfoque para el personal docente y no docente del Centro Educativo Básica Especial Particular Juan Pablo II como parte de la actividad pedagógica profesional de dirección?

\section{METODOLOGÍA}

En función de los objetivos y tareas específicas de la investigación los métodos teóricos utilizados fueron: análisis-síntesis, inducción y deducción, históricológico, que propiciaron la sistematización teórica de los antecedentes y fundamentos históricos, sociológicos y pedagógicos respecto a la educación inclusiva y su nuevo enfoque como parte de la actividad pedagógica profesional de dirección; y como punto de partida en la elaboración de un programa de capacitación.

Los métodos empíricos considerados para obtener información de la educación inclusiva que poseen los docentes y no docentes del Centro Educativo Básica Especial Particular "Juan Pablo II" (CEBEP.
JPII) de la Molina fueron: la Encuesta y la Guía de Observación.

\section{MARCO TEORICO}

Esta nueva concepción de la Educación Especial se encuentra más cercana a la auténtica acción educativa, dirigida a las personas de todas las edades y en ámbitos educativos formales y no formales. Desde esta nueva perspectiva la Educación Especial, ya no está separada de la Educación General, sino más bien forma parte importante de una misma realidad al servicio del alumnado, cuya finalidad es satisfacer sus necesidades educativas especiales, acentuando su rol en el estudio y la observación de cómo se dan en este sector de alumnos los proceso de enseñanza y aprendizaje. Fomentando la lucha contra la exclusión y buscando la igualdad de oportunidades, promoviendo la integración y participación; oponiéndose a lo que comúnmente sucede, la expulsión de alumnos y alumnas con deficiencias leves de las escuelas regulares y negándose a aceptar a aquellos que tienen alguna discapacidad o problemas de aprendizaje, ya sea por lentitud, por atención o por cualquier otra causa.

Si bien es cierto que cada día se realizan procesos sistemáticos para la inclusión hay mucha resistencia a la integración de la educación especial a la escuela regular, por ello los nuevos enfoques y políticas educativas tanto en el ámbito internacional como nacional, abogan por la transformación de las escuelas en espacios donde todos los niños y niñas puedan aprender juntos. Para ello es necesario que los sistemas educativos garanticen el desarrollo de las capacidades esenciales, que promuevan la participación e integración social.

La preparación docente y no docente es un componente esencial de la actividad pedagógica orientada a lograr la educación inclusiva y su nuevo enfoque en el Perú. Sin una capacitación adecuada, para ampliar y fortalecer los programas de intervención para la atención rápida, oportuna, eficiente, no se podrá realizar el proceso de educación inclusiva.

El desafío actual demanda crear cada día, las condiciones para que las instituciones educativas realicen procesos de actualización, de aprendizaje, de innovación; con la intervención de los directivos, de los propios docentes, de los padres de familia, de representantes de la comunidad que asuman que la educación es un derecho que le asiste a toda 
persona por igual, igualdad que se hace más exigente cuando se trata de niños y niñas con habilidades especiales que merecidamente necesitan que sean tratados con mayor justicia y equidad.

\section{Programa de Capacitación en la educación inclusiva y su nuevo enfoque para el personal docente y no docente}

Un programa de capacitación en la educación inclusiva y su nuevo enfoque requiere una consideración especial. Nuestra sociedad necesita que profesionales que laboran en el campo de la educación especial, asuman su responsabilidad laboral con un amplio conocimiento, compromiso; con una comunicación que permita un diálogo abierto y positivo, con gran acogida en beneficio de estas personas con necesidades educativas especiales. [5]

Tenemos que considerar el papel importante que juega la familia y el contacto e interrelación con la comunidad local, donde se privilegian valores que es básico considerar. Los compromisos educativos requieren de funciones vinculadas con la escuela, la familia y el medio comunal, de una manera organizada, metódica, positiva, segura, efectiva, que permita una comunicación constante, participación, intervención y relación permanente, como característica de la función social de la comunidad.

El Programa de capacitación en educación inclusiva y su nuevo enfoque se sustenta en el Principio de la vinculación práctica- teórica-práctica transformadora, el Principio de la Sistematización y el Principio del Compromiso.

El programa considera a cada participante como un potencial capaz de poner a disposición todo su esfuerzo, responsabilidad, voluntad, energía, compromiso, entrega, para mejorar la calidad de su labor pedagógica. Es importante que todos los involucrados en programa deban asumir de manera consecuente, sistemática, continúa su preparación, para mejorar no solo su labor profesional, sino también su condición personal.

Esta propuesta estará orientada a desarrollar al máximo las actitudes, capacidades, hábitos, habilidades del personal docente y no docente mediante la capacitación de la educación inclusiva y su nuevo enfoque, sobre todo en el profundo conocimiento de la educación inclusiva y su nuevo enfoque, para que la labor pedagógica se desenvuelva en base a las experiencias ya realizadas y a un sustento teórico práctico que lleven a cumplir con los objetivos y la misión de esta perspectiva. El programa unifica el desarrollo del componente Pedagógico, Cultural y el Ejercicio y análisis. Cabe mencionar dentro de estos fundamentos que la educación inclusiva es una actitud, un sistema de valores y creencias, y no solo una acción o un conjunto de acciones. La inclusión se centra, pues, en cómo apoyar las cualidades y las necesidades de cada uno y de todos los estudiantes en la comunidad escolar para que se sientan bienvenidos y seguros y alcancen el éxito.

El objetivo del programa es preparar al personal docente y no docente en la educación inclusiva y su nuevo enfoque para mejorar la calidad de la educación. A través de la promoción del conocimiento, la comprensión de la educación inclusiva en el personal docente y no docente. Sensibilizar al personal docente y no docente, la familia, a agentes de la comunidad para el desarrollo de la educación inclusiva. Fortalecer el rol de los docentes como agentes promotores de la educación inclusiva en la comunidad. Y estimular la investigación e innovación en atención a la diversidad en las aulas y las instituciones educativas.

La Metodología, será activa, democratizadora y participativa, beneficiará el desarrollo de procesos dinámicos y analíticos del aprendizaje El aprendizaje se realizará en equipo que permitirá el desarrollo grupal, pero al mismo tiempo que el personal, cada participante hará los aportes correspondientes, enriqueciendo el comentario y la discusión particular y del colectivo. Se aplicará el principio del que enseña, al mismo tiempo aprende, gracias a la interacción de los participantes. Establecimiento del cambio como una necesidad inaplazable, en la que todos deben asumir el reto, sin miedo, sin temor, con la ventaja de aprender nuevas ideas, que van a proporcionar grandes beneficios en el campo educativo.

\section{RESULTADOS Y DISCUSIÓN}

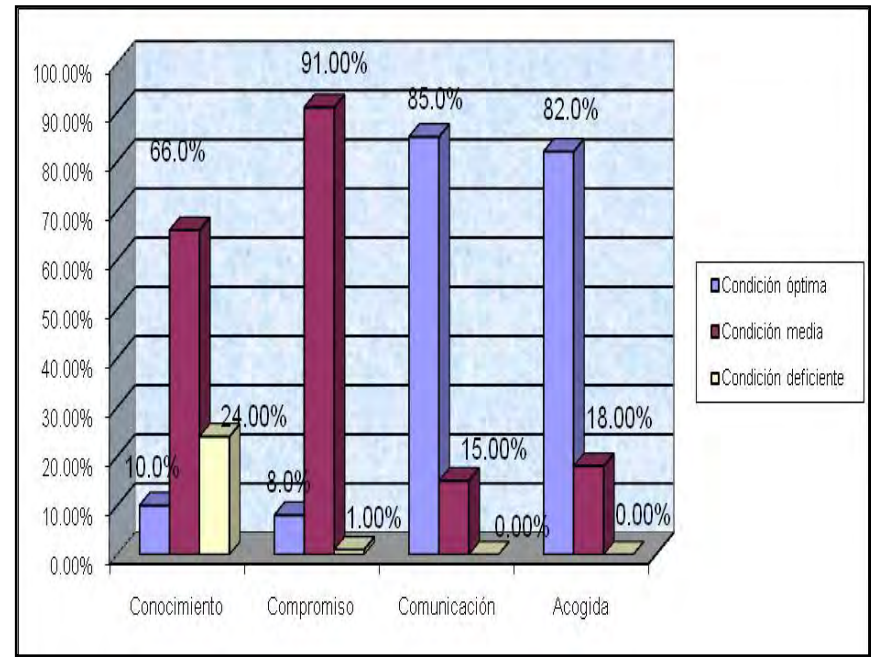

Figura 1: Evaluación a docentes y no docentes 
ECIPERÚ

En la figura 1 se observa que los docentes y no docentes demuestran una condición media en cuanto a los indicadores: Conocimiento y Compromiso, por lo cual se evidencia la necesidad de una formación continua para mejorar su ejercicio profesional en cuanto al nuevo enfoque de la educación inclusiva. Pero en cuanto a los indicadores Comunicación y Acogida la tendencia que prevalece en los docentes y no docentes es la condición óptima, lo cual crea buenas condiciones para la aplicación del Programa de educación inclusiva.

\section{CONCLUSIONES}

La filosofía de la Educación Inclusiva, defiende una educación eficaz para todos sustentando en que los centros y comunidades educativas deben satisfacer las necesidades de todos los alumnos en independencia de sí teniendo o no una discapacidad, es decir mejorar la calidad educativa atendiendo a la diversidad.

El concepto de inclusión se encuentra en proceso de evaluación, sin embargo, el término resulta útil como un agente de cambio conceptual; no basta que los alumnos con necesidades educativas especiales estudien en las escuelas regulares, sino que deben participar activamente en la vida escolar y social de la misma.

La Educación Inclusiva, requiere de amplia perspectiva educativa, que conozca el legado del pasado y tenga en cuenta al alumno de manera global, estableciendo prácticas de enseñanza para todos los alumnos y que los padres de familia sean considerados en los procesos de educación.

Los instrumentos aplicados en la presente investigación permitieron apreciar el diagnóstico del personal docente y no docente del Centro Educativo Básica Especial Particular Juan Pablo II mostrándose una condición media en el personal docente y una condición deficiente en el personal no docente con respecto a la educación inclusiva y su nuevo enfoque. Esta situación nos manifiesta la necesidad de desarrollar el presente programa de capacitación para que el personal cuente con herramientas indispensables para el desarrollo de la educación inclusiva y nuevo enfoque.

\section{RECOMENDACIONES}

Extender el estudio de la educación inclusiva y su nuevo enfoque para un buen perfeccionamiento de la relación escuela-familia-comunidad ya que este aspecto es muy importante en el proceso directivo, tanto para la enseñanza de la educación básica regular en atención a la diversidad.

Se propone la ejecución del programa de capacitación en la Educación Inclusiva y su nuevo enfoque en los docentes que buscan el progreso de la relación del trinomio de la educación.

Proponer este programa de capacitación a escuelas de educación especial y escuelas inclusivas para que la Educación Inclusiva sea exitosa y se tome conciencia de lo que significa.

\section{AGRADECIMIENTOS}

Mi profundo agradecimiento a la Doctora Elisa Herrera y la Dra. Maria Ramos Mellares, quienes me acompañaron con gran profesionalidad y cariño en esta investigación; lo mismo que a todos los que me apoyaron $\mathrm{y}$ alentaron de una $\mathrm{u}$ otra manera en este emocionante proyecto.

\section{REFERENCIAS}

[1] UNESCO. Educación de calidad para todos: un asunto de derechos. Argentina. 2007

[2] Ley General de Educación. Ley Nro. 28044, 2003.

[3] Ministerio de Educación. Propuesta para un Acuerdo Nacional por la Educación 2001, Lima. Comisión para un Acuerdo Nacional por la Educación

[4] Vigotskil L. S. Obras Completas Tomo V Fundamentos de la Defectología Editorial Pueblo y Educación La Habana Cuba 1995.

[5] Arnaiz P.; Herrero, A.; De Haro, R. Trabajo colaborativo entre profesores y atención a la diversidad. Comunidad Educativa, 1999

E-mail: pattytoga@hotmail.com 